\title{
Exogenous melatonin improves growth in hulless barley seedlings under cold stress by influencing the expression rhythms of circadian clock genes
}

\author{
Tianliang Chang ${ }^{1,2,3}$, Yi Zhao ${ }^{1,2,3}$, Hongyan He ${ }^{1,2,3}$, Qianqian Xi ${ }^{1,2,3}$, Jiayi Fu ${ }^{1,2,3}$, Yuwei Zhao ${ }^{\text {Corresp. 1, 2, } 3}$ \\ 1 Provincial Key Laboratory of Biotechnology of Shaanxi Province, Xi'an, China \\ 2 Life Sciences School of Northwest University, Xi'an, China \\ 3 Key Laboratory of Resource Biology and Biotechnology in western China (Ministry of Education), Xi'an, China \\ Corresponding Author: Yuwei Zhao \\ Email address: zhaoyw@nwu.edu.cn
}

Background. Melatonin is a hormone substance that exists in various living organisms. Since it was discovered in the pineal gland of cattle in 1956, the function of melatonin in animals has been roughly clarified. Nevertheless, in plants, the research on melatonin is still insufficient. Hulless barley (Hordeum vulgare L. var. nudum hook. f.) is a crop that originates from cultivated barley in the east, usually grown on the Qinghai-Tibet Plateau, becoming the most important food crop in this area. Although the genome and transcriptome research of highland barley has gradually increased recently years, there are still many problems about how hulless barley adapts to the cold climate of the QinghaiTibet Plateau. Methods. In this study, we set three temperature conditions of $25^{\circ} \mathrm{C}, 15^{\circ} \mathrm{C}$ and $5^{\circ} \mathrm{C}$ to treat the hulless barley seedlings, and at the same time soaked the hulless barley seeds with a $1 \mu \mathrm{M}$ melatonin solution for 12 hours before the hulless barley seeds germinated. Afterwards, the growth and physiological indicators of hulless barley seedlings under different treatment conditions were determined. Meanwhile, the qRT-PCR method was used to determine the transcription level of the hulless barley circadian clock genes under different treatment conditions under continuous light conditions. Results. The results showed the possible mechanism by which melatonin pretreatment can promote the growth of hulless barley under cold stress conditions by studying the effect of melatonin on the rhythm of the circadian clock system and some physiological indicators. The results revealed that the application of $1 \mu \mathrm{M}$ melatonin could alleviate the growth inhibition of hulless barley seedlings caused by cold stress. In addition, exogenous melatonin could also restore the circadian rhythmic oscillation of circadian clock genes, such as HvCCA1 and HVTOC1, whose circadian rhythmic phenotypes were lost due to environmental cold stress. Additionally, the results confirmed that exogenous melatonin even reduced the accumulation of key physiological indicators under cold stress, including malondialdehyde 
and soluble sugars. Discussion. Overall, these findings revealed an important mechanism that exogenous melatonin alleviated the inhibition of plant vegetative growths either by restoring the disrupted circadian rhythmic expression oscillations of clock genes, or by regulating the accumulation profiles of pivotal physiological indicators under cold stress. 
2 Exogenous melatonin improves growth in hulless barley seedlings under cold stress by

3 influencing the expression rhythms of circadian clock genes

4 Tianliang Chang ${ }^{1,2,3}$, Yi Zhao ${ }^{1,2,3}$, Hongyan He ${ }^{1,2,3}$, Qianqian Xi ${ }^{1,2,3}$, Jiayi Fu ${ }^{1,2,3}$ and

5 Yuwei Zhao ${ }^{1,2,3, *}$

6

$7 \quad{ }^{1}$ Provincial Key Laboratory of Biotechnology of Shaanxi Province, Xi'an, China

$8{ }^{2}$ Life Sciences School of Northwest University, Xi'an, China

$9 \quad{ }^{3}$ Key Laboratory of Resource Biology and Biotechnology in western China (Ministry of

10 Education), Xi'an, China

11

Corresponding Author:

13 Yuwei Zhao

141 Provincial Key Laboratory of Biotechnology of Shaanxi Province, Xi'an, 710069, China

152 Life Sciences School of Northwest University, Xi'an, 710069, China

163 Key Laboratory of Resource Biology and Biotechnology in western China (Ministry of

17 Education), Xi'an, 710069, China

18 Email address: zhaoyw@nwu.edu.cn

19

20

21

22

23

24

25

26

27

28

29

30

31

32

33

34

35

36

37

38

39

40 
41 Abstract

42 Background. Melatonin is a hormone substance that exists in various living organisms. Since it 43 was discovered in the pineal gland of cattle in 1956, the function of melatonin in animals has 44 been roughly clarified. Nevertheless, in plants, the research on melatonin is still insufficient. 45 Hulless barley (Hordeum vulgare L. var. nudum hook. f.) is a crop that originates from cultivated 46 barley in the east, usually grown on the Qinghai-Tibet Plateau, becoming the most important 47 food crop in this area. Although the genome and transcriptome research of highland barley has 48 gradually increased recently years, there are still many problems about how hulless barley adapts 49 to the cold climate of the Qinghai-Tibet Plateau.

50 Methods. In this study, we set three temperature conditions of $25^{\circ} \mathrm{C}, 15^{\circ} \mathrm{C}$ and $5^{\circ} \mathrm{C}$ to treat the 51 hulless barley seedlings, and at the same time soaked the hulless barley seeds with a $1 \mu \mathrm{M}$ 52 melatonin solution for 12 hours before the hulless barley seeds germinated. Afterwards, the 53 growth and physiological indicators of hulless barley seedlings under different treatment conditions were determined. Meanwhile, the qRT-PCR method was used to determine the transcription level of the hulless barley circadian clock genes under different treatment conditions under continuous light conditions.

Results. The results showed the possible mechanism by which melatonin pretreatment can promote the growth of hulless barley under cold stress conditions by studying the effect of melatonin on the rhythm of the circadian clock system and some physiological indicators. The results revealed that the application of $1 \mu \mathrm{M}$ melatonin could alleviate the growth inhibition of hulless barley seedlings caused by cold stress. In addition, exogenous melatonin could also restore the circadian rhythmic oscillation of circadian clock genes, such as $H v C C A 1$ and HVTOC1, whose circadian rhythmic phenotypes were lost due to environmental cold stress. Additionally, the results confirmed that exogenous melatonin even reduced the accumulation of key physiological indicators under cold stress, including malondialdehyde and soluble sugars. Discussion. Overall, these findings revealed an important mechanism that exogenous melatonin alleviated the inhibition of plant vegetative growths either by restoring the disrupted circadian rhythmic expression oscillations of clock genes, or by regulating the accumulation profiles of pivotal physiological indicators under cold stress.

\section{Introduction}

Melatonin is a hormone that is ubiquitously distributed in living organisms including animals, plants and algae (Tekbas et al. 2008). In animals, melatonin is involved in the regulatory process of many physiological behaviors through the synchronization of the circadian rhythm, such as the regulation of sleep-wake cycle, blood pressure, food intake, mood, locomotor activities, the number of immune cells in blood and reactive oxygen species scavenging processes (Nawaz et al. 2015). In plants, it is reported to have a wide range of functions involved in a number of physiological processes during either the vegetative or the reproductive growth stages of plants, such as promotion of seed germination, acceleration of seedling growth and regulation of plant senescence and cell death (Agathokleous et al. 2019). In addition, the application of low doses of 
81 exogenous melatonin $(<10 \mu \mathrm{M})$ to the culture medium can promote the growth of maize seedlings 82 by increasing the photosynthetic efficiency (Zhao et al. 2015). Similarly, the inhibition of the 83 expression of the $S N A T$ gene which encodes an N-acetyltransferase enzyme involved in seedlings or their final yield in rice. Meanwhile, SNAT-deficient rice seedlings with reduced endogenous melatonin levels also exhibit a phenotype that is more sensitive to abiotic stresses, such as cold and salt stress than wild type (Byeon \& Back 2016). Under various abiotic stress conditions, such as cold, drought, salt stress, etc., melatonin plays an important role in inhibiting plant ROS production after stress (Turk et al. 2014; Zhang et al. 2014). In Malus hupehensis, melatonin reduces ROS-induced oxidative damage by directly scavenging $\mathrm{H}_{2} \mathrm{O}_{2}$ and enhancing the activity of antioxidant enzymes (such as ascorbate peroxidase, catalase and peroxidase) (Li et al. 2012). Additionally, it has been reported that exogenous melatonin can enhance the freezing resistance of Arabidopsis thaliana by inducing the expression of CBF/DREB (Shi et al. 2016).

Due to the day-night cycle caused by the Earth's rotation, plants naturally undergo a circadian rhythm with a period $\approx 24 \mathrm{~h}$ (Millar 2016; Nohales \& Kay 2016). The circadian rhythms in plants can usually be maintained under constant condition, such as constant light, mainly due to the self-sustaining nature of the endogenous circadian clock. The endogenous circadian clock system in plants usually consists of three parts: a complex core oscillator composed of interlocked transcriptional feedback loops, an environmental time clue input pathway, and the output pathway which delivers biorhythmic information generated by the core oscillator to the downstream activities, such as metabolism and growth (Montaigu et al. 2010). In plants, the biological events controlled by the biological clock systems involve basic physiological and biochemical processes, such as photosynthesis, leaf movement, cell growth, gene expression and stress response, etc. A complete plant circadian clock model has been established in A. thaliana. More than 20 circadian clock-associated genes have been identified in the $A$. thaliana genome, including MYELOBLASTOSIS (MYB)-related genes CIRCADIAN CLOCK ASSOCIATED 1 $(C C A 1)$ and LATE ELONGATED HYPOCOTYL ( $L H Y)$, the PSEUDO RESPONSE REGULATORS (PRRs; including PRR5, PRR7 and PRR9), TIMING OF CAB EXPRESSION 1 (TOC1 / PRR1), and the members of the evening complex; LUX ARRHYTHMO $(L U X)$ / PHYTOCLOCK 1 (PCL1), EARLY FLOWERING (ELF3) and ELF4, etc (Calixto et al. 2015). This model reveals that the $A$. thaliana core oscillator consists of several interlocked transcriptional feedback loops. Under normal conditions, the protein expression products of the early morning genes $C C A 1$ and $L H Y$ inhibited the expression of the night gene TOCl (PRRl) at dawn, whereas the accumulation of TOC1 expression products inhibited the expression of $C C A 1$ and $L H Y$ genes in the night. These genes and their expression products form a negative feedback control loop and serve as the core oscillator of the $A$. thaliana circadian clock system.

CCA1/LHY can also form a morning negative feedback loop with PRR9/PRR7, two members of the PRR family. Acting as a transcriptional factor, the heterodimer of CCA1 and LHY activates the transcription of PRR9 and PRR7 (Capovilla et al. 2015; Park et al. 2012). In turn, the accumulated PRR9/PRR7 proteins directly inhibit the transcription of the CCA1 and LHY genes, 
121

122

123

124

125

126

127

128

129

130

131

132

133

134

135

136

137

138

139

140

141

142

143

144

145

146

147

148

149

150

151

152

153

154

155

156

157

158

159

and also alleviate the inhibition of the TOC1 transcription caused by CCA1/LHY. Accordingly, this negative feedback loop drives the plant circadian clock system, by shifting from the morning phase to the afternoon phase. Subsequently, the accumulated TOC1 protein can trigger the formation of the evening negative feedback loop by combining with the promoter regions of $L U X$ and ELF4 that encodes two core proteins in the evening complex (Calixto et al. 2015; Huang et al. 2012).

Although the molecular components of the circadian clocks in various living organisms are not conserved across species, most of the circadian clock oscillators work through a similar mechanism of transcription/translation feedback loops (Loudon 2012). The circadian clock genes have been identified in some important cereal crops, such as rice and maize. These clock genes in monocotyledonous plants have been found to share high homology with the circadian clock genes in A. thaliana and even display similar rhythmic expression patterns. Recent genomics and transcriptomics studies in barley have confirmed the existence of orthologous circadian clock genes of $A$. thaliana and Oryza sativa with similar rhythmic expression patterns and amino acid sequences in barley (Calixto et al. 2015; Campoli et al. 2012). These findings suggest that most components of the endogenous circadian clock system in barley possibly share same features with those reported in other cereal crops circadian clocks.

Hulless barley (Hordeum vulgare L. var. nudum hook. f.), also known as highland barley, is a cultivar of the oriental cultivated barley, which originates from and is still cultivated mainly in the regions around the Tibet-Qinghai plateau. Indeed, it has been cultivated as the most important staple crop on the Tibet-Qinghai Plateau for 3,500 years (Zeng et al. 2018). Compared with the fertile land in the low altitude plain areas with mild and humid climates, the harsh environment of the Tibet-Qinghai Plateau is challenging for the growth of most common cereal crops. Many studies have been conducted to investigate the mechanism of multiple stresstolerances of hulless barley under various abiotic stresses, such as salinity stress, drought and high temperature stress (Torun 2019). In addition, hulless barley whole genome and transcriptome sequencing studies have also investigated the main mechanism of tolerance to different abiotic stresses in this plant (Wei et al. 2016; Zeng et al. 2016; Zeng et al. 2015). However, we are still far from uncovering the underlying causes of why hulless barley, rather than any other better-yielding cereal crops, is better adapted to the harsh environment in the habitats with highest average altitudes on this planet, which have led to their cultivation as an irreplaceable food crop species by the local farmers in the Tibet-Qinghai regions.

In this study, to investigate the role of exogenous melatonin in the regulation of circadian rhythmic expression of circadian clock genes under cold stresses, we evaluated expression rhythm of clock genes in hulless barley seedlings either with or without exogenous melatonin under different temperature conditions.

\section{Materials \& Methods \\ Materials and growth condition}

Peer) reviewing PDF | (2020:08:52003:3:0:NEW 16 Dec 2020) 
160 The hulless barley used in the study was Kunlun 12, which was a generous gift from Dr. Tao He

161

162

163

164

165

166

167

168

169

170

171

172

173

174

175

176

177

178

179

180

181

182

183

184

185

186

187

188

189

190

191

192

193

194

195

196

197

198

199

(Qinghai University, Xining, Qinghai province, China). The seeds were first rinsed in running tap water for $10 \mathrm{~min}$, and then soaked in $75 \%$ alcohol for $30 \mathrm{~s}$. Subsequently, the seeds were sterilized with $0.1 \% \mathrm{HgCl}_{2}$ for $10 \mathrm{~min}$, and thoroughly washed 5 times with plenty of sterile water. Base on some previous studies on melatonin (Han et al. 2017) and Figure S1, the sterilized seeds were then separately soaked in $1 \mu \mathrm{M}$ melatonin (MT) or distilled water (mock) for $12 \mathrm{~h}$. The hulless barley seeds were then transplanted into $7 \mathrm{~cm}$ length $* 7 \mathrm{~cm}$ wide $* 10 \mathrm{~cm}$ height dark seedling boxes with sterile water-moistened medical gauze and a clear plastic cover. Germination was carried out in the dark at $25^{\circ} \mathrm{C}$ for the following $2 \mathrm{~d}$. Then, the culture condition was switched to constant light photoperiodic illumination provided by cool white fluorescent light with a density of $100 \mu \mathrm{mol} \cdot \mathrm{m}^{-2} \bullet \mathrm{s}^{-1}$ for a week. Subsequently, the seedlings were randomly divided into three groups and transplanted to individual growth chambers at various temperatures of $25^{\circ} \mathrm{C}$ (Normal), $15^{\circ} \mathrm{C}$ (Low temperature) or $5{ }^{\circ} \mathrm{C}$ (Cold) and the same 100 $\mu \mathrm{mol} \cdot \mathrm{m}^{-2} \cdot \mathrm{s}^{-1} 12 \mathrm{~h} / 12 \mathrm{~h}$ light/dark photoperiodic illumination condition for $2 \mathrm{~d}$. To avoid the effects of diurnal light changes, the illumination for all the growth chamber was then switched to $100 \mu \mathrm{mol} \cdot \mathrm{m}^{-2} \bullet \mathrm{s}^{-1}$ constant light by cool white fluorescent light during the following experimental procedure. According to different processing conditions, the experimental materials were divided into the following 6 groups: $25^{\circ} \mathrm{C}$ group, $25^{\circ} \mathrm{C}+\mathrm{MT}$ group, $15^{\circ} \mathrm{C}$ group, $15^{\circ} \mathrm{C}+\mathrm{MT}$ group, $5^{\circ} \mathrm{C}$ group and $5{ }^{\circ} \mathrm{C}+\mathrm{MT}$ group. A more detail description is given in Figure S2. Starting from the time point at which the light was on (Circadian Time, $\mathrm{CT}_{0}$ ), about $100 \mathrm{mg}$ leave tissues were harvested every $4 \mathrm{~h}$ continuously during the following 3 days. All the plant samples, isolated at each time point for subsequent analysis, were immediately stored at $-80^{\circ} \mathrm{C}$ after a brief deep freezing in liquid nitrogen.

\section{Effect of exogenous melatonin on the germination rate of hulless barley seeds}

After treatment as described above by $1 \mu \mathrm{M}$ melatonin or distilled water, the hulless barley seeds were randomly divided into mock or MT group. The seed germination rates of the different tests were determined at $25^{\circ} \mathrm{C}$.

\section{Determination of the effects of melatonin treatment on plant vegetative growth}

After treatment as described above by $1 \mu \mathrm{M}$ melatonin or distilled water, the seedlings were randomly divided into three groups and transplanted to individual growth chambers at various temperatures of 25,15 or $5^{\circ} \mathrm{C}$ and the same $100 \mu \mathrm{mol} \cdot \mathrm{m}^{-2} \cdot \mathrm{s}^{-1} 12 \mathrm{~h} / 12 \mathrm{~h} \mathrm{light} /$ dark photoperiodic illumination condition for $5 \mathrm{~d}$. Then, their morphological indices, such as root length, leaf length, fresh or dry weight of each plantlet were measured.

\section{Determination of endogenous melatonin contents in hulless barley seedlings}

An acetone-methanol method of Pape and Lüning (Pape \& Lüning 2006) was used to assay endogenous melatonin contents in $1.0 \mathrm{~g}$ leaf tissue from each individual seedling that harvested at $\mathrm{CT}_{0}$ and $\mathrm{CT}_{72}$. First, the leaf tissue sample of the hulless barley was fully homogenized to a fine powder in liquid nitrogen with a mortar and pestle. Then, $5 \mathrm{ml}$ of extraction buffer (mixture of acetone, methanol and water at a volume ratio of 89:10:1) was added to the powder, and the grinding of the tissue homogenate was continued on ice for $5 \mathrm{~min}$ in the dark. Subsequently, the

Peer) reviewing PDF | (2020:08:52003:3:0:NEW 16 Dec 2020) 
200

201

202

203

204

205

206

207

208

209

210

211

212

213

214

215

216

217

218

219

220

221

222

223

224

225

226

227

228

229

230

231

232

233

234

235

236

237

238

239

supernatant was collected by centrifugation at 4,500 g for $5 \mathrm{~min}$ in a refrigerated centrifuge and transferred to a new centrifuge tube containing $0.5 \mathrm{~mL}$ of $1 \%$ trichloroacetic acid (TCA) to precipitate the protein. Ultimately, the melatonin content in the supernatant from the different groups of hulless barley seedlings was determined using an Extraction-Melatonin ELISA kit (RE 54021; IBL International GmbH, Hamburg, Germany). To avoid the degradation of melatonin by natural light, all the experiments involving this compound were conducted in a dark room.

\section{Quantitative real-time PCR (qPCR) analysis and rhythm analysis of circadian clock genes}

\section{in hulless barley seedlings}

Total RNA from plant tissue samples was extracted with an RNAiso Plus kit (Takara, Dalian, China). Then, the extracted RNA samples were used to as templates for the subsequent reverse transcription reactions carried out using a PrimeScript ${ }^{\mathrm{TM}}$ RT reagent Kit with gDNA Eraser (Takara). The synthesized cDNAs were purified using the MiniBEST DNA Fragment Purification Kit Ver. 4.0 (Takara), and stored at $-80{ }^{\circ} \mathrm{C}$ freezers until the subsequent qPCR analyses were performed.

Using primers specific for the different circadian clock genes listed in Table S1 in supplement file, all the qPCR reactions were performed on a CFX96 Real-Time PCR Detection System (BioRad Laboratories Inc., Hercules, CA, USA). A TB Green Premix Ex Taq ${ }^{\text {TM }}$ II kit (Takara) was used to perform the amplifications by a two-step method. All samples were first pre-denatured at $94{ }^{\circ} \mathrm{C}$ for $30 \mathrm{~s}$, followed by 40 cycles of denaturation at $94{ }^{\circ} \mathrm{C}$ for $5 \mathrm{~s}$, annealing and elongation at $56^{\circ} \mathrm{C}$ for $30 \mathrm{~s}$ with a read of fluorescence intensity from SYBR ${ }^{\mathrm{TM}}$ Green at the end of elongation process in each reaction. The $\mathrm{Cq}$ value for the qPCR amplification of individual samples is expressed as the mean value \pm standard deviation (SD) from 3 independent biological replicates.

The $\mathrm{Cq}$ value data from $72 \mathrm{~h}$ time-course plant samples was uploaded to the online platform for data sharing and period analysis, BioDare2, and processed by a Spectrum Resampling (SR) method with a threshold of period length ranged from 18 to $34 \mathrm{~h}$ and a RAE (relative amplitude error) value (www.biodare.ed.ac.uk) (Ramos-Sánchez et al. 2017; Zielinski et al. 2014). All the samples series with a feedback period data out of this setting threshold after the online processing, were screened as arrhythmia by BioDare2 automatically. Detailed circadian period and RAE (relative amplitude error) analysis results were shown in Figure S3 and S4.

\section{Determination of chlorophyll and carotenoid content in leaves of hulless barley under} different temperature conditions

Fresh leaf tissue samples from hulless barley seedlings in an amount of $0.1 \mathrm{~g}$,were harvested in a set of time-course experiments at $\mathrm{CT}_{0}, \mathrm{CT}_{12}, \mathrm{CT}_{24}, \mathrm{CT}_{36}, \mathrm{CT}_{48}, \mathrm{CT}_{60}$ and $\mathrm{CT}_{72}$. Chlorophyll (Chl) and carotenoid contents in these leaf tissue samples were measured following the method of Lichtenthaler and Wellburn with slight modifications (Lichtenthaler \& Wellburn 1983). After homogenization in $20 \mathrm{~mL}$ of $80 \%$ acetone (v/v) using a pre-cooled mortar and pestle, the homogenate of the leaf tissue was centrifuged at $8,000 \mathrm{~g}$ for $10 \mathrm{~min}$. Then, $3 \mathrm{~mL}$ of the supernatant from each plant tissue sample was taken to measure the absorbance at the wavelengths of 663, 646 and $470 \mathrm{~nm}$ on a UV/VIS T6 spectrophotometer (Persee Analytics, Beijing, China). The contents of chlorophyll and carotenoid were calculated using the 
240 Lichtenthaler and Wellburn formula (Lichtenthaler \& Wellburn 1983) and expressed as mg g ${ }^{-1}$ 241 FW.

242 Determination of free proline, soluble sugars and malondialdehyde (MDA) contents in 243 leaves of hulless barley seedlings under different temperature conditions

244 Proper amounts of leaf tissues of hulless barley seedlings under different temperature conditions

245 were harvested, and used to determine the intracellular levels of free proline, soluble sugars and 246 MDA. The free proline in leaf tissues was extracted and determined using the Mahdavian's 247 method (Mahdavian et al. 2016) with minor modifications. Briefly, $0.5 \mathrm{~g}$ of hulless barley 248 seedling leaves was thoroughly homogenized in $5 \mathrm{~mL}$ of $3 \%$ sulfosalicylic acid solution $(\mathrm{m} / \mathrm{v})$, 249 and centrifuged at $8,000 \mathrm{~g}$ for $10 \mathrm{~min}$. Then, $2 \mathrm{~mL}$ of the supernatant were transferred into a test 250 tube containing a mixture of $2 \mathrm{~mL}$ glacial acetic acid and $2 \mathrm{~mL}$ of acid ninhydrin, and the test 251 tube was incubated in a water bath at $95^{\circ} \mathrm{C}$ for 1 hour. Subsequently, the red-colored reaction 252 products were extracted and purified with $4 \mathrm{~mL}$ of toluene. The optical density (OD) value of the 253 recovered toluene phase solution was measured at the wavelength of $520 \mathrm{~nm}$. The proline 254 content of each plant sample was determined using a standard curve for proline and expressed as $255 \mu \mathrm{mol} \mathrm{g}^{-1} \mathrm{FW}$.

256 The soluble sugars content was measured using the anthrone method (Azarmi et al. 2015).

257 Precisely, $0.5 \mathrm{~g}$ of the leaf tissues was harvested and thoroughly homogenized in $5 \mathrm{~mL}$ of $80 \%$

258 ethanol and centrifuged at $8,000 \mathrm{~g}$ for 15 minutes. Then, $0.1 \mathrm{~mL}$ of the supernatant was

259 accurately aspirated and mixed with $3 \mathrm{~mL}$ of anthrone. The reaction mixture was incubated in a 260 boiling water bath for $30 \mathrm{~min}$ and then cooled on ice. The $\mathrm{OD}_{625}$ value was recorded for each 261 plant samples and used to calculate the soluble sugars content using a standard curve of soluble 262 sugars reagent and expressed as $\mathrm{mg} \mathrm{g}^{-1} \mathrm{FW}$.

263 The MDA content of each hulless barley leaf tissue sample was determined using the 264 thiobarbituric acid assay (Nahar et al. 2015). Briefly, the leaf tissue (0.5 g) was thoroughly

265 homogenized in $5 \mathrm{ml}$ of TCA, and centrifuged at 8,000 $\mathrm{g}$ for $10 \mathrm{~min}$. Then, $2 \mathrm{ml}$ of the 266 supernatant was aspirated and mixed with $2 \mathrm{ml}$ of a $0.5 \%$ thiobarbituric acid solution. The

267 reaction mixture was incubated in a $95^{\circ} \mathrm{C}$ water bath for $30 \mathrm{~min}$, and then immediately cooled on 268 ice. After centrifugation at 5,000 $\mathrm{g}$ for $10 \mathrm{~min}$, a supernatant aliquot was taken to measure the 269 absorbance at 450, 532 and $600 \mathrm{~nm}$. The MDA content was calculated according to the method 270 reported by Nahar (Nahar et al. 2015) and expressed in $\mu \mathrm{mol} \mathrm{g}^{-1} \mathrm{FW}$.

271 Statistical analysis

272 All growth data were subjected to one-way analysis of variance (ANOVA) using the SigmaStat 273 V3.5 software (Systat Software, San Jose, CA, USA). Duncan's multiple range test was used to 274 assess the difference between treatments at a significance level of $\mathrm{P}<0.05$. For gene expression 275 analysis, data analyses involving multiple comparisons were performed using Student's t-test and 276 the SPSS 22.0 software (SPSS Inc., Chicago, IL, USA). $* \mathrm{P}<0.05$, **P $<0.01$.

277 Results

278 Seed germination and growth assay 
279 The low temperature stress inhibited the growth of hulless barley seedlings, while melatonin 280 pretreatment alleviated this inhibition to a certain extent (Figure 1). At first, the germination rate

281

282

283

284

285

286

287

288

289

290

291

292

293

294

295

296

297

298

299

300

301

302

303

304

305

306

307

308

309

310

311

312

313

314

315

316

317

of hulless barley seeds was $57 \%$ at $25^{\circ} \mathrm{C}$ conditions (Figure 2A). The germination rate analysis was carried out in our laboratory at Xi'an, Shaanxi, China with a location of $108.96^{\circ}$ East longitude and $34.28^{\circ}$ North latitude, an altitude of 405 meters and an air pressure of $97 \mathrm{KPa}$. When the hulless barley seeds were pretreated with $1 \mu \mathrm{M}$ exogenous melatonin, the germination rate was significantly increased to $63 \%$ (Figure 2A-B).

We also determined the effects of exogenous melatonin on leaf length, primary root length, fresh weight and dry weight of hulless barley seedlings under different temperature conditions. The results revealed that exogenous melatonin significantly promoted the growth of leaf length and primary root length and increased fresh weight and dry weight of hulless barley seedlings (Figure 2C-F). In particular, under the condition of cold stress, application of exogenous melatonin markedly alleviated the suppressive effects of low environmental temperature on the vegetative growth of either the hulless barley seedlings leaves, or their roots. These results indicated that a suitable concentration of melatonin could confer significant physiological protection on the barley seedlings when they were exposed to cold stress. Meanwhile, It is interesting that the dry weight of hulless barley at $5{ }^{\circ} \mathrm{C}$ is greater than that at 25 and $15{ }^{\circ} \mathrm{C}$, which was same as previous study in hulless barley under salt stress (Ma et al. 2018) .

\section{The rhythmic expression pattern of the circadian clock gene of hulless barley under cold stress}

The expression patterns of the circadian clock genes of hulless barley seedlings were determined at 25,15 and $5{ }^{\circ} \mathrm{C}$. At $25^{\circ} \mathrm{C}$, the expression of the circadian clock genes, including $H v C C A 1$, $H v T O C 1, H v G I, H v L U X, H v P R R 59, H v P R R 73$ and HvPRR95 maintained a robust circadian rhythmic profile for three days. Unexpectedly, unlike previous reports in barley and A. thaliana, the expression of $H v E L F 3$ in hulless barley exhibited an arrhythmic phenotype. At $15^{\circ} \mathrm{C}$, the expression of the morning clock gene $H v C C A 1$ was not affected by the low temperature signals and showed a similar rhythmic expression pattern to that at $25^{\circ} \mathrm{C}$, while the total mRNA abundance of the night clock genes $\mathrm{HvTOCl}$ and $\mathrm{HvGI}$ were significantly downregulated. In contrast, the expression levels of genes encoding key components of the evening complex (EC) of circadian clock in plants, such as $H v L U X$ and $H v E L F 3$, were significantly upregulated. With respect to the PRR genes, although the expression levels of $H v P R R 59, H v P R R 73$ and $H v P R R 95$ were not affected by exposure to $15^{\circ} \mathrm{C}$ (low temperature), the phase of their rhythmic expression pattern was shifted forward. Consistent with expectations, the expression of all the evaluated circadian clock genes was significantly suppressed, and showed arrhythmic phenotypes under cold stress conditions at $5{ }^{\circ} \mathrm{C}$. (Figure 3, Figure S3 and Figure S4).

\section{Effects of melatonin on the rhythmic expression pattern of circadian clock genes in hulless barley}

Peer) reviewing PDF | (2020:08:52003:3:0:NEW 16 Dec 2020) 
318 The effects of exogenous melatonin on the rhythmic expression pattern of the circadian clock

319

320

321

322

323

324

325

326

327

328

329

330

331

332

333

334

335

336

337

338

339

340

341

342

343

344

345

346

347

348

349

350

351

352

353

354

355

356

357

genes under various temperature conditions were evaluated after soaking the seeds of hulless barley in a $1 \mu \mathrm{M}$ melatonin solution. The results showed that at $25^{\circ} \mathrm{C}$, exogenous melatonin remarkably induced the expression level of $H v C C A 1$, the crucial morning clock gene of the plant endogenous circadian clock, to nearly 30 -fold higher than that of untreated mock seedlings. Additionally, exogenous melatonin also slightly inhibited the expression level of HvTOC1, which is the key gene in the evening loop of the plant circadian clock. PRR genes in hulless barley displayed diverse responses to the exogenous melatonin treatments. The expression of $H v P R R 73$ was induced by 2 4 folds, while that of HvPRR59 and HvPRR95 was significantly inhibited by $1 \mu \mathrm{M}$ melatonin. Regarding other evening loop genes, $H v E L F 3$ expression was slightly induced by exogenous melatonin, but the expression of $H v L U X$ and $H v G I$ was suppressed by melatonin to various degrees. In general, exogenous melatonin was found to affect the rhythmic expression patterns of the circadian clock genes by influencing their amplitudes in various degrees at $25^{\circ} \mathrm{C}$. As well as, exogenous melatonin had influenced the period length of clock gene expression at $25^{\circ} \mathrm{C}$ in different manners. As shown in Figure S3, exogenous melatonin treatment significantly decreased the period length of $\mathrm{HvTOCl}$ (about 2.5h), while remarkably increased the period length of $H v P R R 59$ (2.7h) and $H v G I$ (1.9h). (Figure 4, Figure S3 and Figure S4).

Under $15^{\circ} \mathrm{C}$ (low temperature) conditions, the expression levels of the HvCCA1, HvPRR59, $H v P R R 95, H v T O C 1, H v L U X$ and HvELF3 genes in hulless barley seedlings that had been pretreated with $1 \mu \mathrm{M}$ exogenous melatonin, were substantially suppressed compared with those of the seedlings at $25^{\circ} \mathrm{C}$. Among all tested circadian clock genes, the rhythmic expression of some genes was not affected, such as those of HvPRR59 and HvPRR95. However, the peak phase of some others was delayed, such as $H v P R R 73$ and $H v G I$, whereas the peak phase of the evening loop genes $H v T O C 1$ and $H v L U X$ was shifted forward. The circadian rhythmic expression of morning gene $H v C C A 1$ was completely disrupted and showed an arrhythmic pattern in melatonin pretreated hulless barley seedlings ( $\mathrm{RAE}>0.6)$. These results indicated that exogenous melatonin inhibited the expression of most circadian clock genes and influenced the phase of some other clock genes under low temperature conditions. Additionally, these results also suggested that the night clock genes (such as $H v T O C 1$ and $H v L U X$ ) were the potential targets for melatonin pretreatment at $15{ }^{\circ} \mathrm{C}$. Interestingly, the period of all rhythmically expressed gene was extended by exogenous melatonin at $15^{\circ} \mathrm{C}$ (Figure 5, Figure S3 and Figure S4).

Under $5{ }^{\circ} \mathrm{C}$ (cold stress) conditions, the expression of the HvPRR73, HvPRR59, HvPRR95, $H v L U X, H v E L F 3$ and $H v G I$ genes was strongly suppressed by $1 \mu \mathrm{M}$ melatonin treatments and showed arrhythmic phenotype in their time course expression patterns. Remarkably, exogenous melatonin treatment was able to restore the rhythmic expression of the $\mathrm{HvCCAl}$ and $\mathrm{HvTOCl}$ gene to some extent, although their amplitudes were much lower than the $25{ }^{\circ} \mathrm{C}$ group. It was also worth noting that the circadian oscillation of $\mathrm{HvCCAl}$ and $\mathrm{HvTOCl}$ peaked at the subjective

Peer) reviewing PDF | (2020:08:52003:3:0:NEW 16 Dec 2020) 
358

359

360

361

362

363

364

365

366

367

368

369

370

371

372

373

374

375

376

377

378

379

380

381

382

383

384

385

386

387

388

389

390

391

392

393

394

395

396

397

night phase under exogenous melatonin treatment. These results indicated that under cold stress, the appropriate concentration of exogenous melatonin treatment could restore the rhythmicity of the expression of the core circadian clock genes that encode the pacemaker of plant circadian clock in hulless barley. (Figure 6, Figure S3 and Figure S4).

\section{Determination of the chlorophyll and carotenoid contents in leaves of hulless barley} Under conditions at $25^{\circ} \mathrm{C}$, the treatment with $1 \mu \mathrm{M}$ melatonin reduced the chlorophyll and carotenoid contents in the leaves of hulless barley seedlings at most time points, though an unexpected increase of these two photosynthetic pigments by $44 \%$ and $35 \%$ more than the mock seedlings was observed at $\mathrm{CT}_{48}$ in a time course experiment that lasted $3 \mathrm{~d}$.

At $15{ }^{\circ} \mathrm{C}$, the accumulation of chlorophyll and carotenoids showed very similar fluctuation patterns in hulless barley. In addition, at $15^{\circ} \mathrm{C}$, the exogenous melatonin significantly increased the relative amounts of cytosolic chlorophyll and carotenoids in seedling leaves after $\mathrm{CT}_{36}$. For example, triggered by the exogenous melatonin, the accumulation of chlorophyll contents in leaves peaked at the $\mathrm{CT}_{36}$ and $\mathrm{CT}_{60}$ time points by $27 \%$ and $45 \%$, respectively, compared to the mock seedlings.

Exogenous melatonin could also increase the contents of chlorophyll and carotenoids in the leaves of hulless barley under cold stress conditions after $\mathrm{CT}_{24}$ at $5{ }^{\circ} \mathrm{C}$. For example, compared to $5^{\circ} \mathrm{C}$ group, treatment with $1 \mu \mathrm{M}$ melatonin also significantly increased chlorophyll accumulation by $49 \%$ and $35 \%$ at $\mathrm{CT}_{36}$ and $\mathrm{CT}_{60}$, respectively in a time course experiment. These results confirmed that the proper amount of exogenous melatonin contributed to provide a better protection to these key pigments of their photosynthetic systems under low temperature and cold stress conditions (Figure 7A-F).

\section{Determination of the MDA, soluble sugar and free proline content in leaves of hulless barley}

MDA is a stable product of membrane lipid peroxidation, which always occurs during various abiotic stress-response processes in plants. The relative content of MDA in cells has been used either as a general intracellular indicator to ealuate the damage of plant cells under stresses, or as a common physiological indicator to estimate different resistance abilities of individual plant species under various environmental stresses (Leshem 1987). In this study, no noticeable changes in the MDA contents of stressed hulless barley leaves under both $15^{\circ} \mathrm{C}$ and $5{ }^{\circ} \mathrm{C}$ conditions were found when compared to that of the seedlings under $25^{\circ} \mathrm{C}$ (Figure 7G-I). Nevertheless, the contents of intracellular MDA also changed significantly in all the seedlings that have been treated by $1 \mu \mathrm{M}$ melatonin. In particular, at $5{ }^{\circ} \mathrm{C}$, the treatment with melatonin markedly decreased the production of MDA in hulless barley leaves to between 7 and $57 \%$ at different time points (Figure 7G-I).

The soluble sugar content of hulless barley leaves increased significantly with when the environmental temperature dropped to $15{ }^{\circ} \mathrm{C}$ or $5{ }^{\circ} \mathrm{C}$, as shown in Figure 7. However, the treatment of $1 \mu \mathrm{M}$ exogenous melatonin notably reduced the amount of soluble sugars in hulless 
398

399

400

401

402

403

404

405

406

407

408

409

410

411

412

413

414

415

416

417

418

419

420

421

422

423

424

425

426

427

428

429

430

431

432

433

434

435

436

437

barley seedlings under $15^{\circ} \mathrm{C}$ and $5{ }^{\circ} \mathrm{C}$ conditions. In particular, the soluble sugar content in the melatonin-treated seedlings decreased $26 \%$ to that of the mock seedlings under the same cold stress conditions at $5{ }^{\circ} \mathrm{C}$. These results provided direct evidence for exogenous melatonin had enhanced the stress-resistance of hulless barley seedlings on the physiological levels under cold stress (Figure 7J-L).

Various environmental abiotic stresses, such as low temperature, high salt and excessive heavy metals always induced the accumulation of free proline in plant cells as a compatible osmoprotectant (Ashraf \& Foolad 2007). In this study, no significant changes in the free proline content in mock hulless barley seedlings were detected under various temperature conditions. When hulless barley seeds were pretreated with $1 \mu \mathrm{M}$ exogenous melatonin, the free proline content in hulless barley seedlings was reduced to $53 \%$ at $15^{\circ} \mathrm{C}$, meanwhile exogenous melatonin did not significantly influence the proline content in hulless barley seedlings at $25{ }^{\circ} \mathrm{C}$ and $5{ }^{\circ} \mathrm{C}$ (Figure 7M-O).

\section{Discussion}

Cold stress is one of the most severe stresses that strongly inhibits the vegetative growth of hulless barley seedlings (Peppino Margutti et al. 2017). Many studies in A. thaliana (Bajwa et al. 2014), wheat (Turk et al. 2014) and Bermuda grass (Hu et al. 2016) have shown that treatment with the proper concentration of exogenous melatonin clearly alleviates the inhibitory effect of environmental low temperature and cold stress on plant growth. In some studies, the data also shows that higher concentrations of exogenous melatonin treatment would inhibit plant growth (Chen et al. 2009). Consistent with previous reports, we also found that treatment with $1 \mu \mathrm{M}$ exogenous melatonin enhanced cold tolerance in hulless barley and significantly alleviated the plant growth inhibition under low temperature and cold stress conditions. However, the specific molecular mechanism by which melatonin promoted the growth of stressed plant has not been fully elucidated.

The circadian clock is an important system for controlling plant growth. In A. thaliana, more than one-third of genes are directly or indirectly controlled by circadian clock genes under natural growth conditions (Covington et al. 2008). In this study, at $25^{\circ} \mathrm{C}$, the expression of hulless barley circadian clock genes, namely HvCCA1, HvPRR73, HvPRR59, HvPRR95, HvGI, $H v T O C 1$ and $H v L U X$ displayed self-sustained robust rhythmic oscillations. When the seedlings of hulless barley were cultured at $15^{\circ} \mathrm{C}$, the circadian clock genes of hulless barley did maintain their rhythmic expression patterns following the temperature compensation mechanism, an intrinsic feature of all known circadian clock system.

Melatonin is a hormone that is ubiquitously present in many living organisms. Numerous studies have revealed the detail mechanism by which the melatonin plays a crucial role in the regulation of the mammalian circadian rhythms, such as the circadian sleep/wake rhythms (Nawaz et al. 2015). However, the function of melatonin in plants has not been completely elucidated (Arnao \& Hernández-Ruiz 2015). In this study, we found that the main role of melatonin in the regulation of the expression of circadian clock genes is to increase the relative 
438 expression of the morning loop genes, such as $H v C C A 1$, and slightly inhibit that of the evening 439 loop genes, such as $\mathrm{HvTOCl}$ at $25^{\circ} \mathrm{C}$ under constant light. This finding indicated that melatonin

440

441

442

443

444

445

446

447

448

449

450

451

452

453

454

455

456

457

458

459

460

461

462

463

464

465

466

467

468

469

470

471

472

473

474

475

476

477

not only can promote the growth of hulless barley but also affect the expression level of circadian clock genes under normal growth conditions. In previous studies, overexpression of $C C A 1$ was found to significantly accelerate the vegetative growth in A. thaliana (Lau et al. 2011). We hypothesized that the increasing and decreasing expression of morning clock genes plays an important role in the process of vegetative growth acceleration in hulless barley. Under $15^{\circ} \mathrm{C}$ low temperature stress, treatment with exogenous melatonin significantly suppressed the expression of most circadian clock genes. In fact, even the rhythmic expression pattern of the morning loop gene $C C A 1$ was completely lost and also showed substantially decreased relative mRNA levels in seedlings. Regarding the evening loop genes, such as HvTOCl and HvLUX, they maintained their expression rhythms albeit with very dimmed amplitudes and disturbed phases, which were shifted forward at $15^{\circ} \mathrm{C}$. Consistent with our above mentioned hypothesis, no significant differences were found between the vegetative growths of the seedlings from the $15^{\circ} \mathrm{C}$ group and $15^{\circ} \mathrm{C}+\mathrm{MT}$ group, when the expression of the morning gene $H v C C A 1$ was severely suppressed and showed an arrhythmic pattern, while the evening clock genes displayed circadian expression pattern with disturbances in either amplitude and phase features in the melatonin pretreated hulless barley seedlings. Under $5{ }^{\circ} \mathrm{C}$ cold stress conditions, almost all circadian clock genes lost their circadian rhythms. However, the treatment with exogenous melatonin restored the circadian rhythm of $H v C C A 1$ and $H v T O C 1$ to some extent. This is consistent with reports that melatonin inhibits the daytime effects in the dinoflagellate Lingulodinium and that peaks of melatonin appear in nighttime in Chenopodium rubrum L. and green macroalga Ulva sp. (Kolár \& Machácková 2005; Kolář et al. 1997; Tal et al. 2011). When the growth of seedlings was evaluated again, the results showed that the growth of leaves in the melatonin pretreated hulless barley seedlings was significantly higher than that of $5{ }^{\circ} \mathrm{C}$ group seedlings, simultaneously with the partial restore of $\mathrm{HvCCAl}$ and $\mathrm{HvTOCl}$ expression rhythms with dimmed amplitude.

Photosynthetic pigments are important substances that responsible for the absorption, transmission, and transformation of light energy in plant photosynthesis (Ashraf \& Harris 2013). In this study, no significant changes in the chlorophyll and carotenoid contents were detected in hulless barley seedlings that were not treated with melatonin under low temperature and cold stress conditions, compared with the seedlings under normal conditions. Nevertheless, the measurements of photosynthetic pigments showed that melatonin treatment significantly increased the contents of chlorophyll and carotenoids under cold stress condition. These findings indicated that exogenous melatonin can protect the photosystem of hulless barley seedlings against the damages caused by cold stress by increasing the amount of chlorophyll and carotenoids in the cells.

As one of the most important osmoregulatory substances, soluble sugars in plant cells play a pivotal role in the physiological responses to cold stress in various plants and protect plant cells by increasing their cytosolic osmotic potentials, as well as decreasing the freezing point of their

Peer) reviewing PDF | (2020:08:52003:3:0:NEW 16 Dec 2020) 
478 cell matrix (Markovskaya et al. 2010). In this study, the content of soluble sugars in the hulless 479 barley seedlings increased significantly when they were exposed to a low temperature of $15^{\circ} \mathrm{C}$ or $4805^{\circ} \mathrm{C}$, but the treatment with melatonin greatly reduced the content of soluble sugars in hulless 481 barley than that in the $15^{\circ} \mathrm{C}$ and $5^{\circ} \mathrm{C}$ groups.

482 Low temperature or cold stress induce various responses in plants, such as the accumulation of 483 MDA in cells. MDA is the final product of the peroxidation of membrane lipids. Both MDA and

484

485

486

487

488

489

490

491

492

493

494

495

496

497

498

499

500

501

502

503

504

505

506

507

508

509

510

511

512

513

514

515

516

517 soluble sugars have been widely used as indicators to assay the degree of damage caused by various stresses to the plant as well as been utilized to estimate the stress tolerance of various plants to abiotic stresses by researchers (Szabados \& Savouré 2010). However, no noticeable increase in the contents of MDA were detected among hulless barley seedlings that have been cultivated under low temperature or cold stress conditions in this study. These results indicated that, as a local plant adapted to the Tibet-Qinghai plateau, hulless barley had displayed a better resistance to cold stresses than other main cereal crops grown in lower altitude regions. These facts that the treatment with exogenous melatonin could reduce the contents of MDA and soluble sugar under cold stress conditions, also indicated that exogenous melatonin had alleviated the damage to hulless barley seedlings caused by cold stress.

\section{Conclusions}

In summary, under cold stress conditions, treatment with exogenous melatonin can enhance plant resistance to cold stress by regulating the circadian rhythms of the expression profiles of clock genes and accumulation profiles of some key physiological indicators in hulless barley. In addition, melatonin can attenuate the inhibition of plant growth induced by environmental cold stress. Our results indicate that melatonin is an important plant growth regulator, which can be used to improve cold stress tolerance in plants in agricultural production and thus has great application prospects.

\section{References}

Agathokleous E, Kitao M, and Calabrese EJ. 2019. New insights into the role of melatonin in plants and animals. Chemico-Biological Interactions 299:163-167. https://doi.org/10.1016/j.cbi.2018.12.008

Arnao MB, and Hernández-Ruiz J. 2015. Functions of melatonin in plants: a review. Journal of Pineal Research 59:133-150. https://doi.org/10.1111/jpi.12253

Ashraf M, and Foolad MR. 2007. Roles of glycine betaine and proline in improving plant abiotic stress resistance. Environmental and Experimental Botany 59:206-216. https://doi.org/10.1016/j.envexpbot.2005.12.006

Ashraf M, and Harris PJC. 2013. Photosynthesis under stressful environments: An overview. Photosynthetica 51:163-190. https://doi.org/10.1007/s11099-013-0021-6

Azarmi F, Mozafari V, Abbaszadeh Dahaji P, and Hamidpour M. 2015. Biochemical, physiological and antioxidant enzymatic activity responses of pistachio seedlings treated 
518

519

520

521

522

523

524

525

526

527

528

529

530

531

532

533

534

535

536

537

538

539

540

541

542

543

544

545

546

547

548

549

550

551

552

553

554

555

with plant growth promoting rhizobacteria and $\mathrm{Zn}$ to salinity stress. Acta Physiologiae Plantarum 38:21. https://doi.org/10.1007/s11738-015-2032-3

Bajwa VS, Shukla MR, Sherif SM, Murch SJ, and Saxena PK. 2014. Role of melatonin in alleviating cold stress in Arabidopsis thaliana. Journal of Pineal Research 56:238-245. https://doi.org/10.1111/jpi.12115

Byeon Y, and Back K. 2016. Low melatonin production by suppression of either serotonin Nacetyltransferase or $\mathrm{N}$-acetylserotonin methyltransferase in rice causes seedling growth retardation with yield penalty, abiotic stress susceptibility, and enhanced coleoptile growth under anoxic conditions. Journal of Pineal Research 60:348-359. https://doi.org/10.1111/jpi.12317

Calixto CP, Waugh R, and Brown JW. 2015. Evolutionary relationships among barley and Arabidopsis core circadian clock and clock-associated genes. Journal of Molecular Evolution 80:108-119. https://doi.org/10.1007/s00239-015-9665-0

Campoli C, Shtaya M, Davis SJ, and von Korff M. 2012. Expression conservation within the circadian clock of a monocot: natural variation at barley Ppd-H1 affects circadian expression of flowering time genes, but not clock orthologs. BMC Plant Biology 12:97. https://doi.org/10.1186/1471-2229-12-97

Capovilla G, Pajoro A, Immink RG, and Schmid M. 2015. Role of alternative pre-mRNA splicing in temperature signaling. Current Opinion in Plant Biology 27:97-103. https://doi.org/10.1016/j.pbi.2015.06.016

Chen Q, Qi W-b, Reiter RJ, Wei W, and Wang B-m. 2009. Exogenously applied melatonin stimulates root growth and raises endogenous indoleacetic acid in roots of etiolated seedlings of Brassica juncea. Journal of Plant Physiology 166:324-328. https://doi.org/10.1016/j.jplph.2008.06.002

Covington MF, Maloof JN, Straume M, Kay SA, and Harmer SL. 2008. Global transcriptome analysis reveals circadian regulation of key pathways in plant growth and development. Genome Biology 9:R130. https://doi.org/10.1186/gb-2008-9-8-r130

Han QH, Huang B, Ding CB, Zhang ZW, Chen YE, Hu C, Zhou LJ, Huang Y, Liao JQ, Yuan S, and Yuan M. 2017. Effects of Melatonin on Anti-oxidative Systems and Photosystem II in Cold-Stressed Rice Seedlings. Frontiers of Plant Science 8:785. https://doi.org/10.3389/fpls.2017.00785

Hu Z, Fan J, Xie Y, Amombo E, Liu A, Gitau MM, Khaldun ABM, Chen L, and Fu J. 2016. Comparative photosynthetic and metabolic analyses reveal mechanism of improved cold stress tolerance in bermudagrass by exogenous melatonin. Plant Physiol Biochem 100:94-104. https://doi.org/10.1016/j.plaphy.2016.01.008

Huang W, Pérez-García P, Pokhilko A, Millar AJ, Antoshechkin I, Riechmann JL, and Mas P. 2012. Mapping the core of the Arabidopsis circadian clock defines the network structure of the oscillator. Science 336:75-79. https://doi.org/10.1126/science.1219075 
556 Kolár J, and Machácková I. 2005. Melatonin in higher plants: occurrence and possible functions.

557

558

559

560

561

562

563

564

565

566

567

568

569

570

571

572

573

574

575

576

577

578

579

580

581

582

583

584

585

586

587

588

589

590

591

592

593

594 Journal of Pineal Research 39:333-341. https://doi.org/10.1111/j.1600079X.2005.00276.X

Kolář J, Macháčková I, Eder J, Prinsen E, van Dongen W, van Onckelen H, and Illnerová H. 1997. Melatonin: Occurrence and daily rhythm in Chenopodium rubrum. Phytochemistry 44:1407-1413. https://doi.org/10.1016/S0031-9422(96)00568-7

Lau OS, Huang X, Charron JB, Lee JH, Li G, and Deng XW. 2011. Interaction of Arabidopsis DET1 with CCA1 and LHY in mediating transcriptional repression in the plant circadian clock. Molecular Cell 43:703-712. https://doi.org/10.1016/j.molcel.2011.07.013

Leshem YaY. 1987. Membrane phospholipid catabolism and Ca2+ activity in control of senescence. Physiologia Plantarum 69:551-559. https://doi.org/10.1111/j.13993054.1987.tb09239.x

Li C, Wang P, Wei Z, Liang D, Liu C, Yin L, Jia D, Fu M, and Ma F. 2012. The mitigation effects of exogenous melatonin on salinity-induced stress in Malus hupehensis. Journal of Pineal Research 53:298-306. https://doi.org/10.1111/j.1600-079X.2012.00999.x

Lichtenthaler HK, and Wellburn AR. 1983. Determinations of total carotenoids and chlorophylls $\mathrm{a}$ and $\mathrm{b}$ of leaf extracts in different solvents. Biochemical Society Transactions 11:591592. https://doi.org/10.1042/bst0110591

Loudon AS. 2012. Circadian biology: a 2.5 billion year old clock. Current Biology 22:R570-571. https://doi.org/10.1016/j.cub.2012.06.023

Ma Y, Wang P, Chen Z, Gu Z, and Yang R. 2018. GABA enhances physio-biochemical metabolism and antioxidant capacity of germinated hulless barley under $\mathrm{NaCl}$ stress. Journal of Plant Physiology 231. https://doi.org/10.1016/j.jplph.2018.09.015

Mahdavian K, Ghaderian SM, and Schat H. 2016. Pb accumulation, Pb tolerance, antioxidants, thiols, and organic acids in metallicolous and non-metallicolous Peganum harmala $\mathrm{L}$. under $\mathrm{Pb}$ exposure. Environmental and Experimental Botany 126:21-31. https://doi.org/10.1016/j.envexpbot.2016.01.010

Markovskaya EF, Sherudilo EG, Galibina NA, and Sysoeva MI. 2010. The role of carbohydrates in the responses of chilling-sensitive plants to short- and long-term low-temperature treatments. Russian Journal of Plant Physiology 57:641-647. https://doi.org/10.1134/S1021443710050067

Millar AJ. 2016. The Intracellular Dynamics of Circadian Clocks Reach for the Light of Ecology and Evolution. Annual Review of Plant Biology 67:595-618. https://doi.org/10.1146/annurev-arplant-043014-115619

Montaigu A, Tóth R, and Coupland G. 2010. Plant development goes like clockwork. Trends in Genetics 26:296-306. https://doi.org/10.1016/j.tig.2010.04.003

Nahar K, Hasanuzzaman M, Alam MM, and Fujita M. 2015. Roles of exogenous glutathione in antioxidant defense system and methylglyoxal detoxification during salt stress in mung bean. Biologia Plantarum 59:745-756. https://doi.org/10.1007/s10535-015-0542-x 
595 Nawaz MA, Huang Y, Bie Z, Ahmed W, Reiter RJ, Niu M, and Hameed S. 2015. Melatonin:

596

597

598

599

600

601

602

603

604

605

606

607

608

609

610

611

612

613

614

615

616

617

618

619

620

621

622

623

624

625

626

627

628

629

630

631

632

633

634 Current Status and Future Perspectives in Plant Science. Frontiers of Plant Science 6:1230. https://doi.org/10.3389/fpls.2015.01230

Nohales MA, and Kay SA. 2016. Molecular mechanisms at the core of the plant circadian oscillator. Nature Structural \& Molecular Biology 23:1061-1069. https://doi.org/10.1038/nsmb.3327

Pape C, and Lüning K. 2006. Quantification of melatonin in phototrophic organisms. Journal of Pineal Research 41:157-165. https://doi.org/10.1111/j.1600-079X.2006.00348.x

Park MJ, Seo PJ, and Park CM. 2012. CCA1 alternative splicing as a way of linking the circadian clock to temperature response in Arabidopsis. Plant Signal Behav 7:1194-1196. https://doi.org/10.4161/psb.21300

Peppino Margutti M, Reyna M, Meringer MV, Racagni GE, and Villasuso AL. 2017. Lipid signalling mediated by PLD/PA modulates proline and $\mathrm{H}(2) \mathrm{O}(2)$ levels in barley seedlings exposed to short- and long-term chilling stress. Plant Physiol Biochem 113:149-160. https://doi.org/10.1016/j.plaphy.2017.02.008

Ramos-Sánchez JM, Triozzi PM, Moreno-Cortés A, Conde D, Perales M, and Allona I. 2017. Real-time monitoring of PtaHMGB activity in poplar transactivation assays. Plant Methods 13:50. https://doi.org/10.1186/s13007-017-0199-x

Shi H, Wei Y, and He C. 2016. Melatonin-induced CBF/DREB1s are essential for diurnal change of disease resistance and CCA1 expression in Arabidopsis. Plant Physiology and Biochemistry 100:150-155. https://doi.org/10.1016/j.plaphy.2016.01.018

Szabados L, and Savouré A. 2010. Proline: a multifunctional amino acid. Trends in Plant Science 15:89-97. https://doi.org/10.1016/j.tplants.2009.11.009

Tal O, Haim A, Harel O, and Gerchman Y. 2011. Melatonin as an antioxidant and its semi-lunar rhythm in green macroalga Ulva sp. Journal of Experimental Botany 62:1903-1910. https://doi.org/10.1093/jxb/erq378

Tekbas OF, Ogur R, Korkmaz A, Kilic A, and Reiter RJ. 2008. Melatonin as an antibiotic: new insights into the actions of this ubiquitous molecule. Journal of Pineal Research 44:222226. https://doi.org/10.1111/j.1600-079X.2007.00516.x

Torun H. 2019. Time-course analysis of salicylic acid effects on ROS regulation and antioxidant defense in roots of hulled and hulless barley under combined stress of drought, heat and salinity. Physiologia Plantarum 165:169-182. https://doi.org/10.1111/ppl.12798

Turk H, Erdal S, Genisel M, Atici O, Demir Y, and Yanmis D. 2014. The regulatory effect of melatonin on physiological, biochemical and molecular parameters in cold-stressed wheat seedlings. Plant Growth Regulation 74:139-152. https://doi.org/10.1007/s10725-0149905-0

Wei Z, Zeng X, Qin C, Wang Y, Bai L, Xu Q, Yuan H, Tang Y, and Nyima T. 2016. Comparative Transcriptome Analysis Revealed Genes Commonly Responsive to Varied Nitrate Stress in Leaves of Tibetan Hulless Barley. Frontiers of Plant Science 7:1067. https://doi.org/10.3389/fpls.2016.01067 
635

636

637

638

639

640

641

642

643

644

645

646

647

648

649

650

651

652

653

654

655

656

657

658

659

660

661

662
Zeng X, Bai L, Wei Z, Yuan H, Wang Y, Xu Q, Tang Y, and Nyima T. 2016. Transcriptome analysis revealed the drought-responsive genes in Tibetan hulless barley. BMC Genomics 17:386. https://doi.org/10.1186/s12864-016-2685-3

Zeng X, Guo Y, Xu Q, Mascher M, Guo G, Li S, Mao L, Liu Q, Xia Z, Zhou J, Yuan H, Tai S, Wang Y, Wei Z, Song L, Zha S, Li S, Tang Y, Bai L, Zhuang Z, He W, Zhao S, Fang X, Gao Q, Yin Y, Wang J, Yang H, Zhang J, Henry RJ, Stein N, and Tashi N. 2018. Origin and evolution of qingke barley in Tibet. Nat Commun 9:5433. https://doi.org/10.1038/s41467-018-07920-5

Zeng X, Long H, Wang Z, Zhao S, Tang Y, Huang Z, Wang Y, Xu Q, Mao L, Deng G, Yao X, Li X, Bai L, Yuan H, Pan Z, Liu R, Chen X, WangMu Q, Chen M, Yu L, Liang J, DunZhu D, Zheng Y, Yu S, LuoBu Z, Guang X, Li J, Deng C, Hu W, Chen C, TaBa X, Gao L, Lv X, Abu YB, Fang X, Nevo E, Yu M, Wang J, and Tashi N. 2015. The draft genome of Tibetan hulless barley reveals adaptive patterns to the high stressful Tibetan Plateau. Proceedings of the National Academy of Sciences of the United States of America 112:1095-1100. https://doi.org/10.1073/pnas.1423628112

Zhang HJ, Zhang N, Yang RC, Wang L, Sun QQ, Li DB, Cao YY, Weeda S, Zhao B, Ren S, and Guo YD. 2014. Melatonin promotes seed germination under high salinity by regulating antioxidant systems, $\mathrm{ABA}$ and $\mathrm{GA}_{4}$ interaction in cucumber (Cucumis sativus L.). Journal of Pineal Research 57:269-279. https://doi.org/10.1111/jpi.12167

Zhao H, Su T, Huo L, Wei H, Jiang Y, Xu L, and Ma F. 2015. Unveiling the mechanism of melatonin impacts on maize seedling growth: sugar metabolism as a case. Journal of Pineal Research 59:255-266. https://doi.org/10.1111/jpi.12258

Zielinski T, Moore AM, Troup E, Halliday KJ, and Millar AJ. 2014. Strengths and limitations of period estimation methods for circadian data. PloS One 9:e96462. https://doi.org/10.1371/journal.pone.0096462 


\section{Figure 1}

Figure 1. Growth status of hulless barley seedlings under different treatment conditions.

$25^{\circ} \mathrm{C}, 25^{\circ} \mathrm{C}+\mathrm{MT}, 15^{\circ} \mathrm{C}, 15^{\circ} \mathrm{C}+\mathrm{MT}, 5^{\circ} \mathrm{C}$ and $5^{\circ} \mathrm{C}+\mathrm{MT}$.

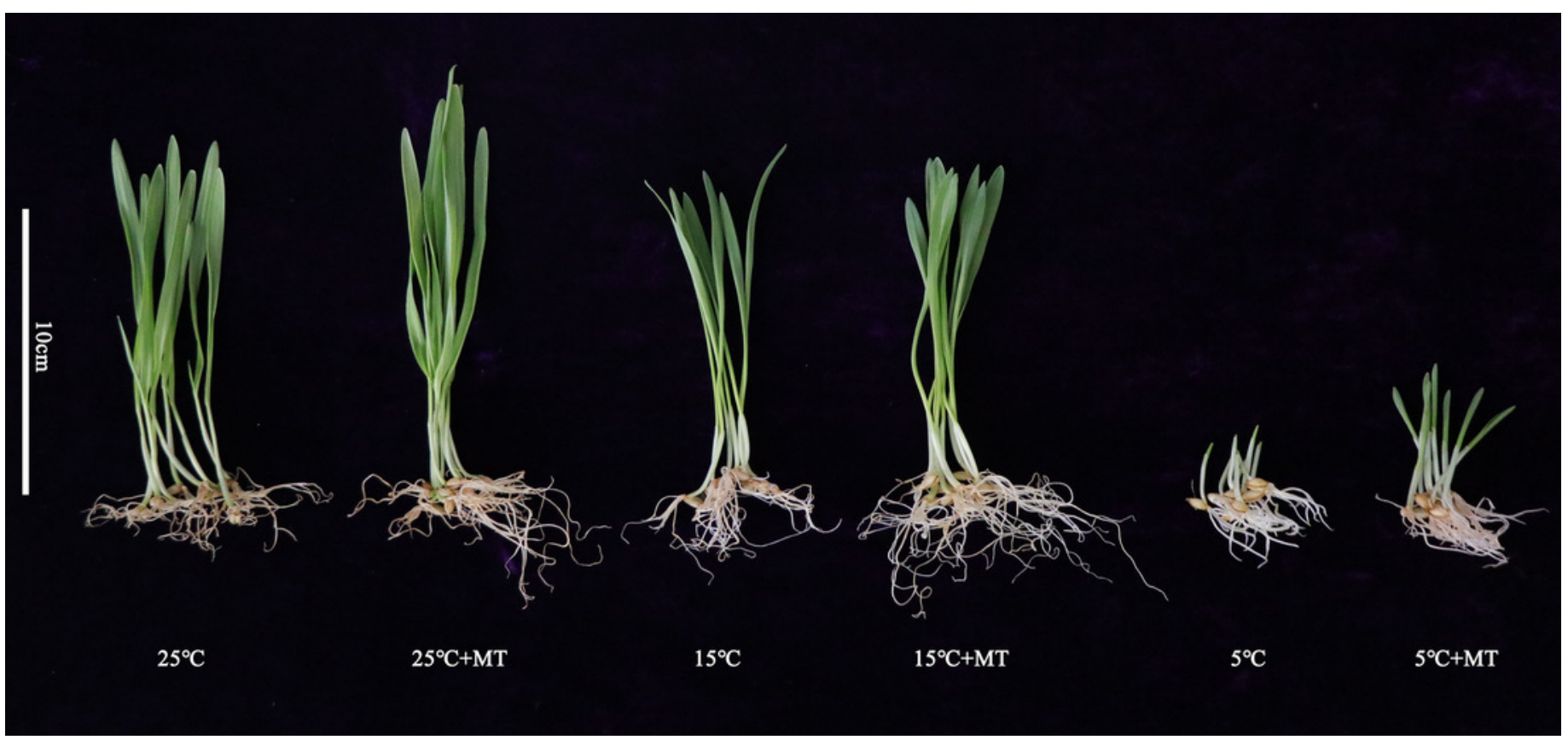


Figure 2

Figure 2. Effects of exogenous melatonin on growth.

(A) Germination rate of hulless barley seeds, (B) Melatonin content, (C) Length of primary leaf, (D) Length of root, (E) Fresh weight of seedlings, (F) Dry weight of seedlings. Different lowercase letters in all figures indicate significant difference at $\mathrm{P}<0.05$ level. Data are expressed as the means \pm SEM. 

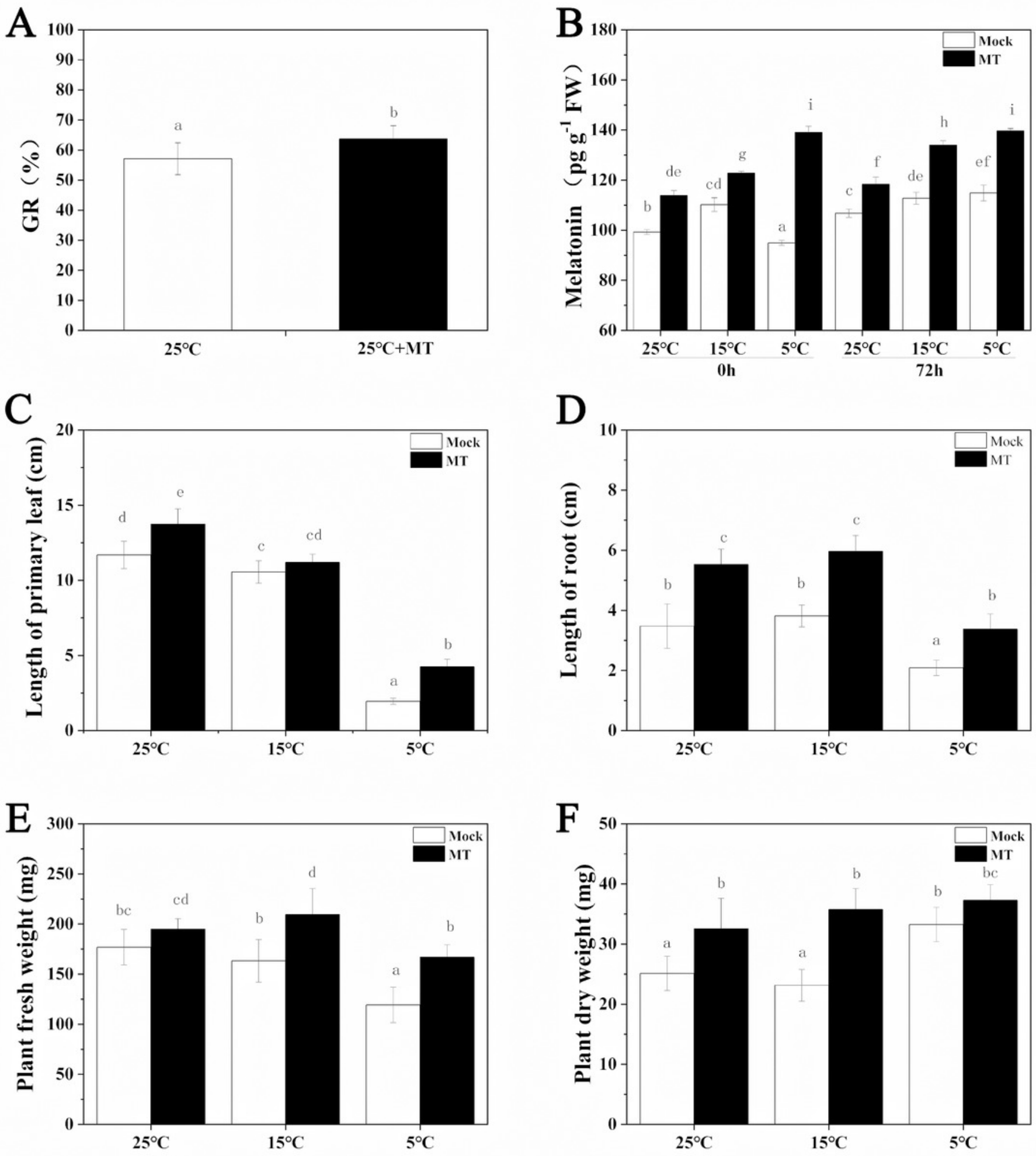
Figure 3

Figure 3. Expression pattern of circadian clock genes in hulless barley seedlings at various temperatures.

Expression of circadian clock gene measured by RT-qPCR analysis at $25{ }^{\circ} \mathrm{C}$ (black lines), 15 ${ }^{\circ} \mathrm{C}$ (red lines) and or $5{ }^{\circ} \mathrm{C}$ (blue lines). Total RNA was extracted from 3 biological replicates. Average expression is shown relative to $E F-1 \alpha$, error bars represent the standard error. Horizontal axis labels indicate circadian time (CT) after a 12h/12h light/dark entrainment. The open rectangles under horizontal axis represent the subjective day and the gray rectangles represent the subjective night.
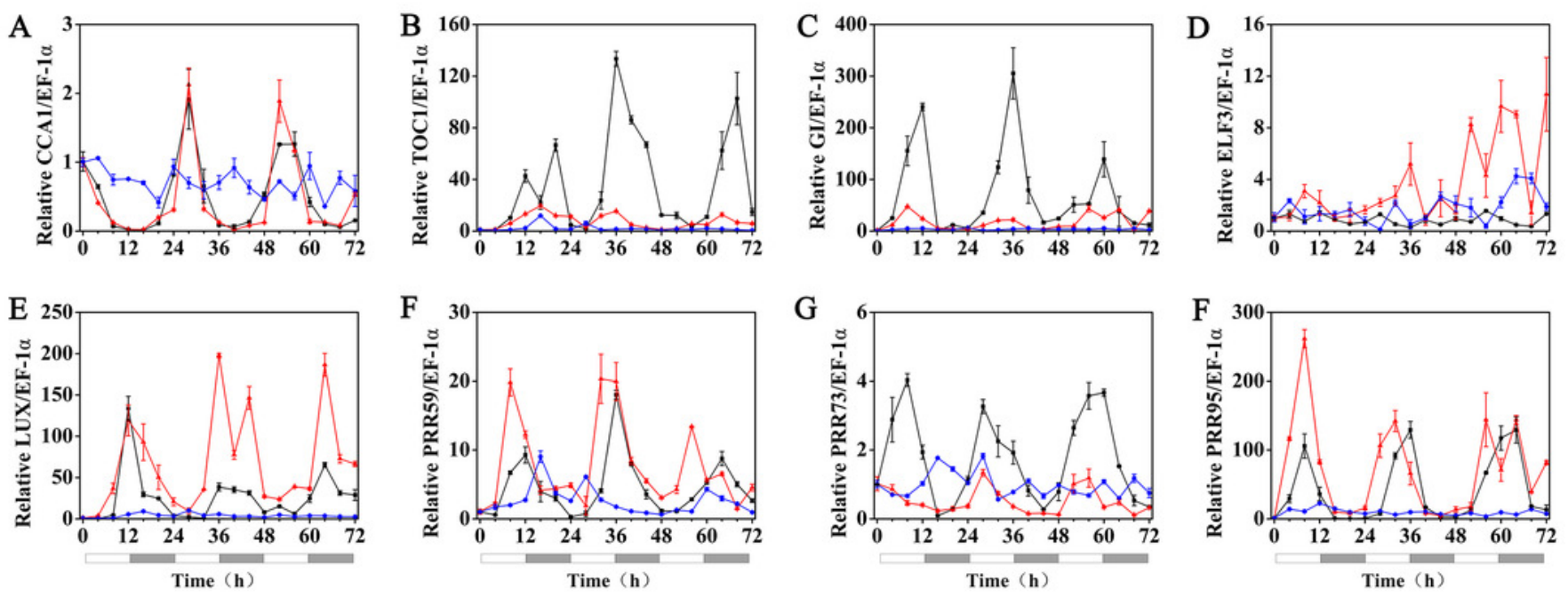


\section{Figure 4}

Figure 4. Expression of circadian clock genes in hulless barley seedlings treated with 1 $\mu \mathrm{M}$ melatonin at $25^{\circ} \mathrm{C}$.

Plots of measured expression profiles of circadian clock genes for the $25{ }^{\circ} \mathrm{C}$ group (black lines) and $25{ }^{\circ} \mathrm{C}+\mathrm{MT}$ group (red lines) hulless barley seedlings. Total RNA for the analysis of the clock genes was extracted from 3 biological replicates. Average Cq values from 3 independent RT-qPCR amplifications were used to determine the relative expression levels of target genes after calibration with a reference gene, EF-1 $\alpha$. Error bars represent standard errors. Asterisks indicate significant differences in different treatment groups $(* \mathrm{P}<0.05$, **P $<0.01)$.
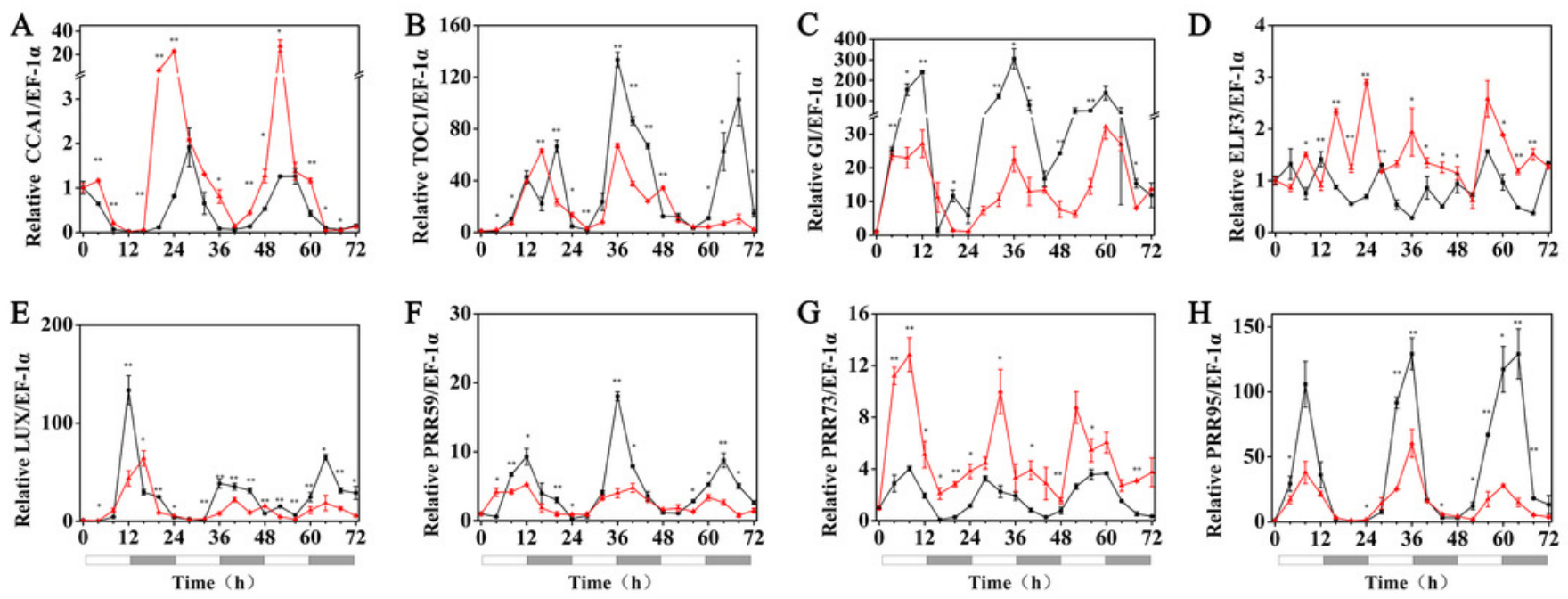
Figure 5

Figure 5. Expression of circadian clock genes in hulless barley seedlings treated with 1 $\mu \mathrm{M}$ melatonin at $15^{\circ} \mathrm{C}$.

Plots of measured expression profiles of circadian clock genes for the $15{ }^{\circ} \mathrm{C}$ group (black lines) and $15{ }^{\circ} \mathrm{C}+\mathrm{MT}$ group (red lines). Total RNA for the analysis of the clock genes was extracted from 3 biological replicates. Average Cq values from 3 independent RT-qPCR amplifications were used to determine the relative expression levels of target genes after calibration with a reference gene, EF-1 $\alpha$. Error bars represent standard errors. Asterisks indicate significant differences in different treatment groups (*P $<0.05, * * \mathrm{P}<0.01$ ).
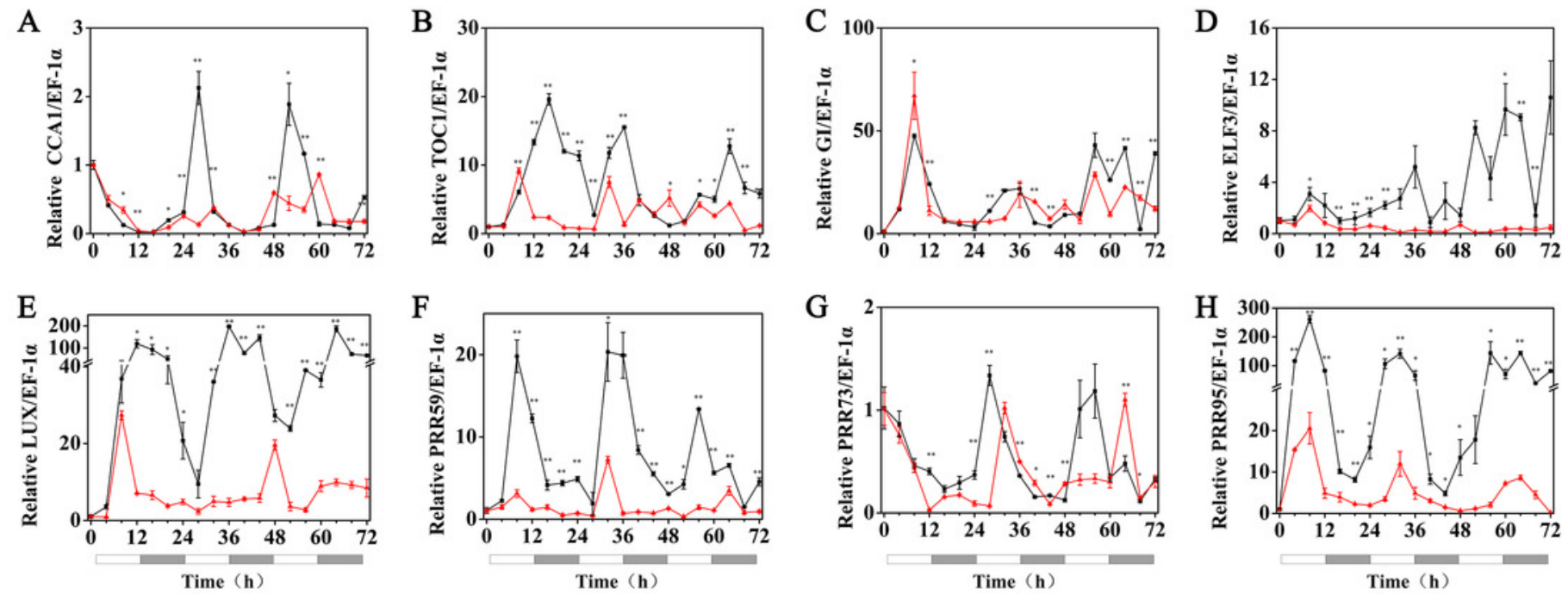


\section{Figure 6}

Figure 6. Expression of circadian clock genes in hulless barley seedlings treated with 1 $\mu \mathrm{M}$ melatonin at $5{ }^{\circ} \mathrm{C}$.

Plots of measured (solid lines) expression profiles of circadian clock genes for the $5^{\circ} \mathrm{C}$ group (black lines) and $5{ }^{\circ} \mathrm{C}+\mathrm{MT}$ group (red lines).Total RNA for the analysis of the clock genes was extracted from 3 biological replicates. Average Cq values from 3 independent RT-qPCR amplifications were used to determine the relative expression levels of target genes after calibration with a reference gene, EF-1 $\alpha$. Error bars represent standard errors. Asterisks indicate significant differences in different treatment groups ( $* \mathrm{P}<0.05, * * \mathrm{P}<0.01$ ).
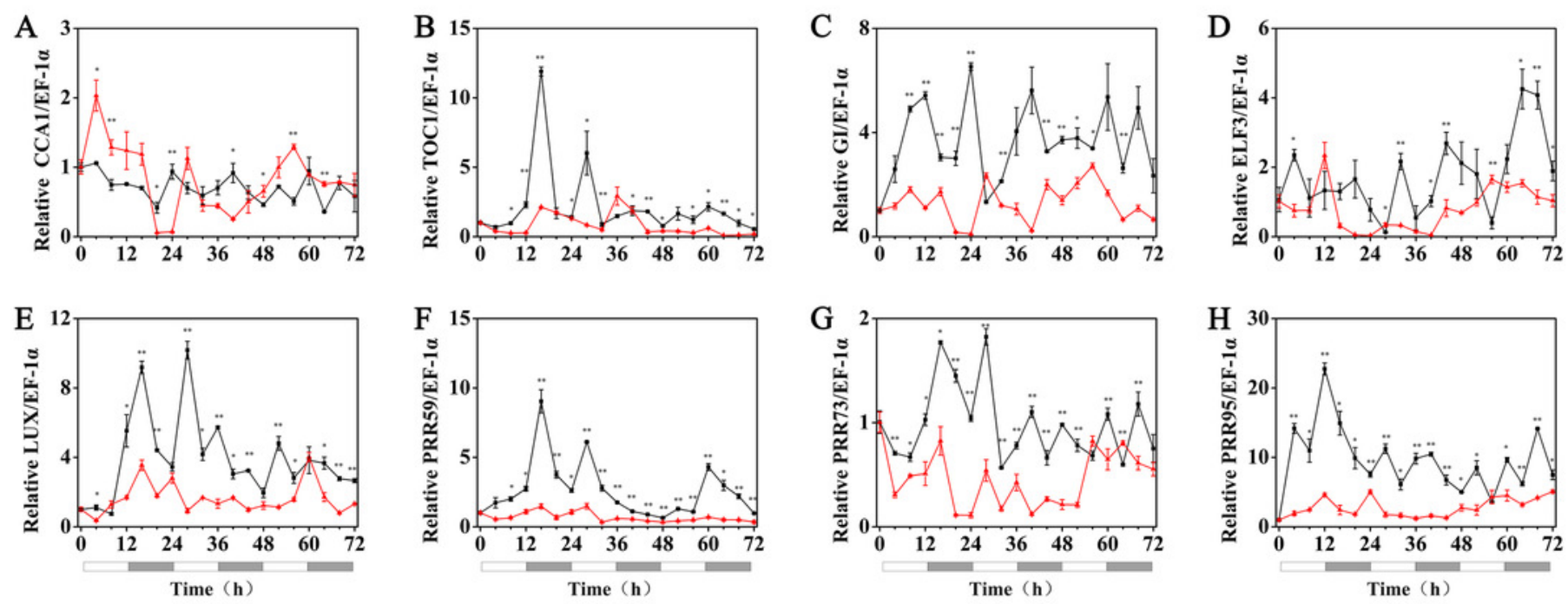
Figure 7

Figure 7. Concentration of chlorophyll, Carotenoids, MDA, soluble sugar and proline in hulless barley leaf tissues from the $25^{\circ} \mathrm{C}, 25^{\circ} \mathrm{C}+\mathrm{MT}, 15{ }^{\circ} \mathrm{C}, 15{ }^{\circ} \mathrm{C}+\mathrm{MT}, 5^{\circ} \mathrm{C}$ and 5 ${ }^{\circ} \mathrm{C}+\mathrm{MT}$ groups.

Asterisks indicate significant differences in different treatment groups $\left(* \mathrm{P}<0.05,{ }^{* * P}<0.01\right)$. Data are expressed as the mean \pm SEM $(n=3)$. 

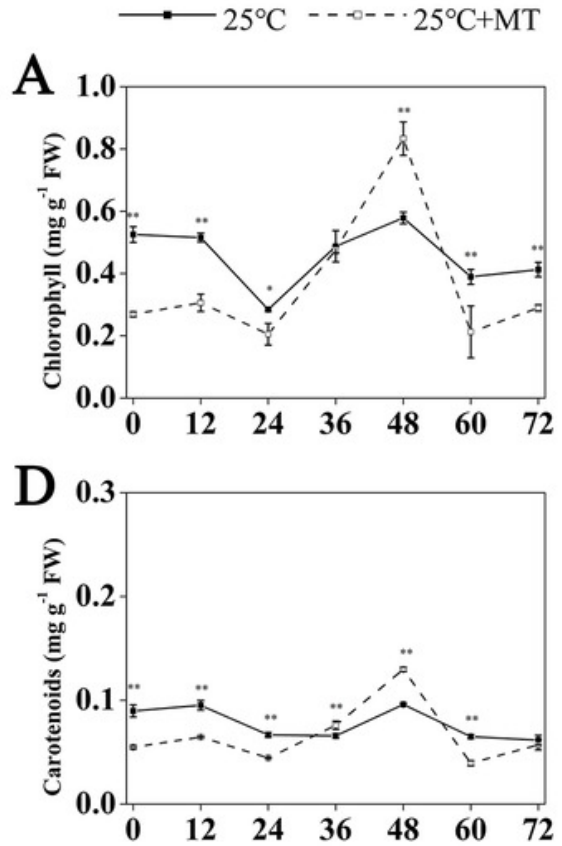

G
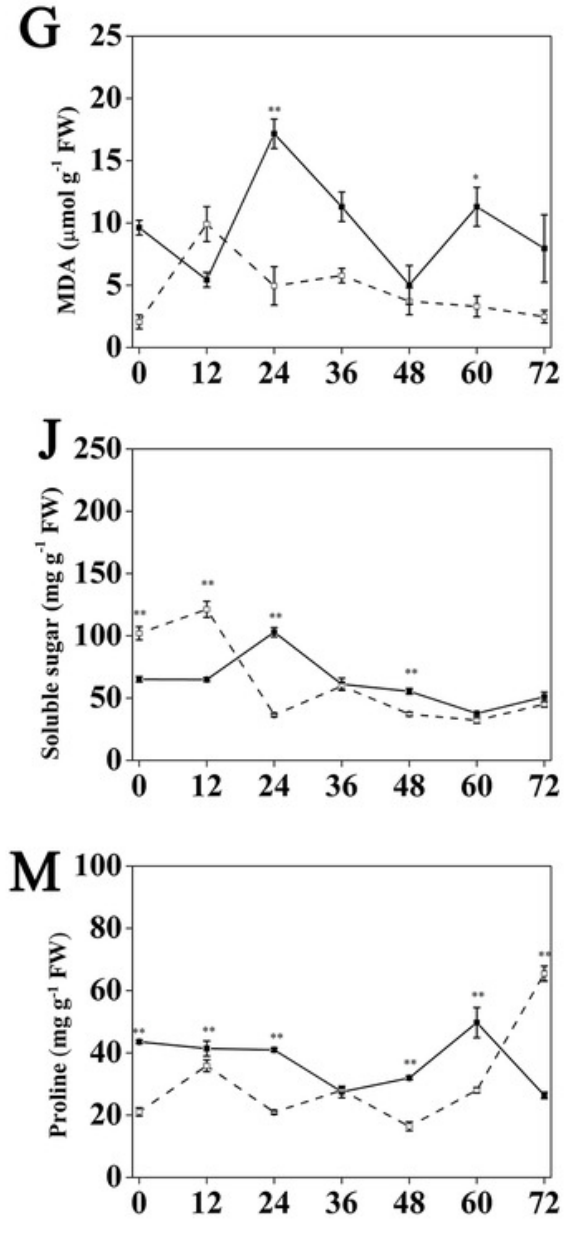

Time (h)
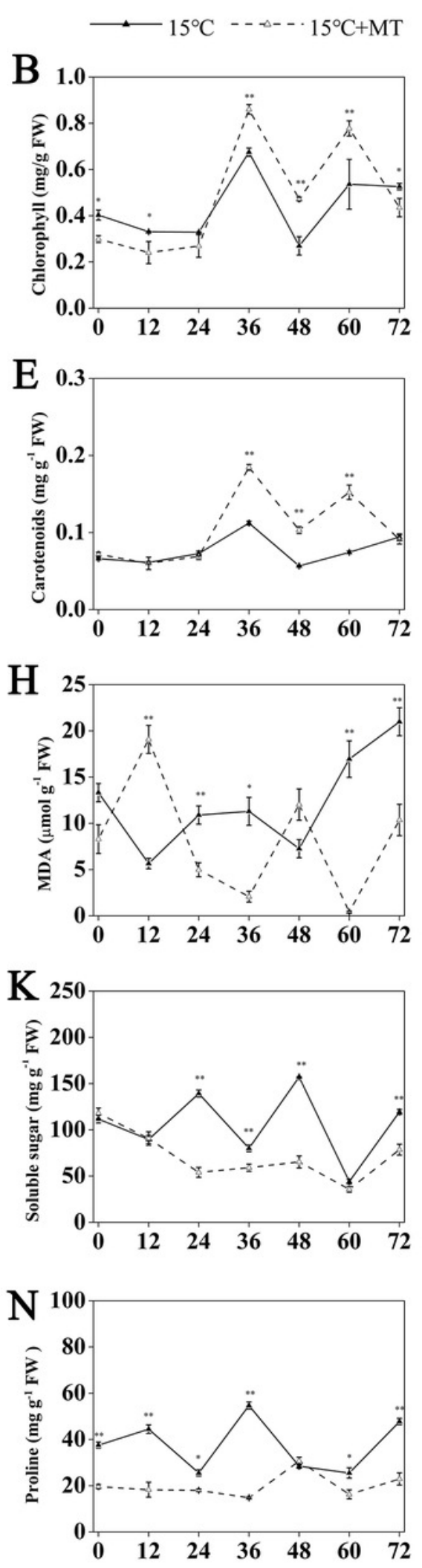

Time (h)
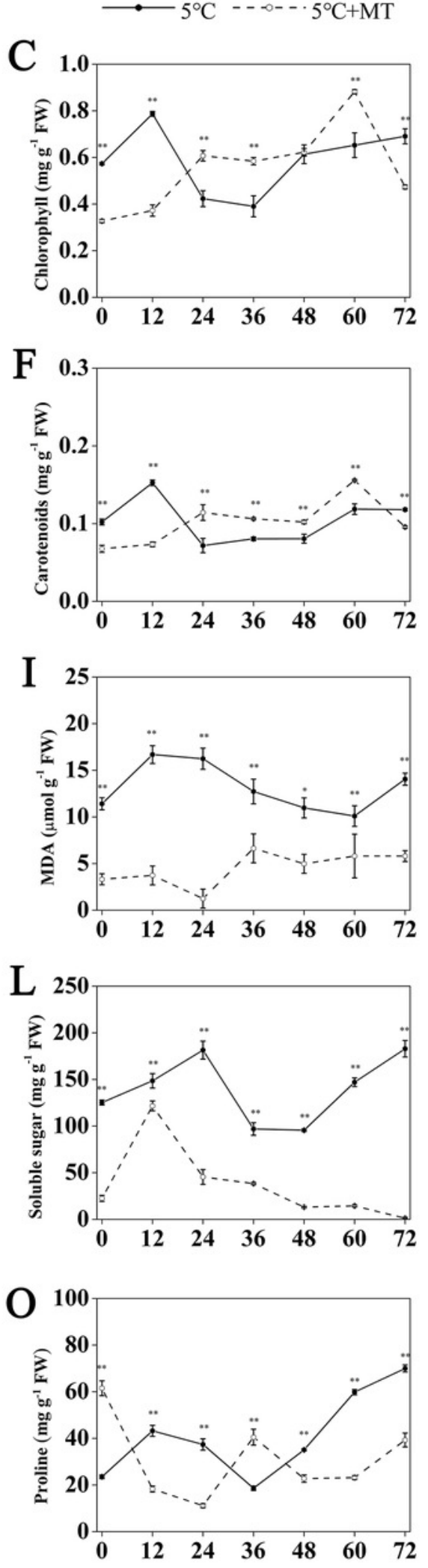

Time (h) 